\title{
EL DERECHO DE ACCESO A LA INFORMACIÓN PÚBLICA EN LA JURISPRUDENCIA DEL TEDH: UN DERECHO INSTRUMENTAL IMPRESCINDIBLE PARA LA EFICACIA DEL CONVENIO DESDE LA TEORÍA GENERAL DE LOS DERECHOS
}

\author{
MARIO HERNÁNDEZ RAMOS \\ Profesor Titular de Derecho Constitucional \\ Universidad de Salamanca
}

\section{SUMARIO}

I. Introducción. II. El debate sobre la existencia de un derecho de acceso a la información pública en el CEDH. Un derecho de carácter instrumental. III. El derecho de acceso a la información pública como instrumento para la eficacia de otros derechos. IV. Contornos del derecho de acceso a la información desde la teoría general de derechos fundamentales. V. A modo de conclusión.

\section{INTRODUCCIÓN}

El derecho de acceso a la información pública ha suscitado una gran discusión en el ámbito académico, político y social. La razón hay que encontrarla en las ansias de cambio y transformación democrática que lleva experimentando la sociedad europea de los países parte del Consejo de Europa. En algunas sociedades, en las que las estructuras democráticas están muy asentadas, se demanda un incremento de la calidad democrática; en otras sociedades, jóvenes democracias con grandes retos por afrontar, se persigue alcanzar estándares respetables embridando los poderes públicos. En ambos escenarios, en los que la democracia representativa está en crisis y se demanda de manera creciente mecanismos más participativos, el protagonista es una ciudadanía informada y crítica, exigiendo una rendición de cuentas de los poderes públicos efectiva. Todas estas aspiraciones requieren tener información, superando las formas tradicionales de obtenerla, como los medios de comunicación de masas. La sociedad en primera persona, a través de organizaciones gubernamentales, o simplemente de personas individuales, quiere tener acceso a la información con relevancia pública que pueda afectarla ${ }^{1}$.

1 Bustos Gisbert, R., Calidad democrática. Reflexiones constitucionales desde la teoría, la realidad y el deseo, Marcial Pons, 2017, pp. 63-97. 
Por tanto, el acceso a la información pública es un mecanismo imprescindible para la conformación de una sociedad informada y crítica. Es, en consecuencia, una condición sine qua non para una democracia de calidad. La cristalización de un derecho que posibilite este acceso ha sido una lucha de conquista de la sociedad frente a la opacidad estatal. Muchos Estados han positivizado este derecho desde hace décadas ${ }^{2}$, comenzando por Suecia ${ }^{3}$; otros lo han reconocido de manera muy reciente como es el caso de España ${ }^{4}$. En los escenarios donde se ha demandado una mejora de la calidad democrática o la mera consolidación de la misma, a través de un efectivo control del poder público, siempre ha jugado un papel destacado el acceso a la información en posesión del poder público.

De manera contraria a como ha sucedido con otros derechos o en otras latitudes ${ }^{5}$, el Tribunal Europeo de Derechos Humanos (en adelante TEDH) no ha sido un referente en esta materia. No obstante, en las dos últimas décadas el Tribunal de Estrasburgo ha prestado atención de manera creciente en la medida de las posibilidades de un tribunal internacional encorsetado por un texto de 1950 centrado en derechos civiles que no reconocía explícitamente un derecho de acceso a la información pública.

En efecto, en el Convenio Europeo de Derecho Humanos (en adelante CEDH) no puede encontrarse un derecho de acceso a la información pública formulado de manera expresa. Si bien es cierto que se discutió en ciertos momentos de los trabajos preparatorios, la inexistencia es clara.

Aun así, el TEDH, y también la desaparecida Comisión, han tenido que hacer frente a demandas de ciudadanos europeos que exigían el acceso a información pública en muy diferentes circunstancias, alegando para ello la eventual vulneración de diferentes derechos formulados explícitamente en el CEDH, como la vida privada, la libertad de expresión o la tutela judicial efectiva entre otros, dejando una jurisprudencia muy casuística y en ocasiones poco uniforme.

El TEDH ha intentado aclarar en la decisión de Gran Sala Magyar Helsinki Bizottság c. Hungría, de 8 de noviembre de 2016 el debate sobre la existencia y ámbito de un pretendido derecho de acceso a la información pública. De esta manera, el TEDH reconoce la existencia de tal derecho, pero sólo como derecho instrumental. Además, la Gran Sala se circunscribe únicamente al ámbito del art. $10 \mathrm{CEDH}$.

En nuestra opinión, y sin negar en absoluto su importancia, esta decisión es insuficiente para comprender todo el alcance y el ámbito del derecho de acceso a la información pública en el seno del CEDH, por lo que se abordará, a la luz de la teoría general de derechos fundamentales, los elementos configuradores de este derecho de carácter instrumental a raíz de la jurisprudencia del TEDH que no se limita al ámbito del art. $10 \mathrm{CEDH}$, sino prestando atención también a los arts. $8 \mathrm{CEDH}$ y en menor medida al 6.1 CEDH.

2 Véase Estudio comparado sobre normativa internacional en materia de derecho de acceso a la información pública, INAP, 2016.

3 Ley de Libertad de Prensa de Suecia de 1766.

4 Ley 19/2013, de 9 de diciembre, de transparencia, acceso a la información pública y buen gobierno.

5 Paradigmática es la sentencia de la CIDH, caso Claude Reyes y otros vs. Chile, 19 de septiembre de 2006. 


\section{EL DEBATE SOBRE LA EXISTENCIA DE UN DERECHO DE ACCESO A LA INFORMACIÓN PÚBLICA EN EL CEDH. UN DERECHO DE CARÁCTER INSTRUMENTAL}

Las primeras reflexiones sobre el derecho de acceso a la información pública se han de dedicar a su misma existencia, pues sería contrario a la seguridad jurídica y una actuación ultra vires de legislación judicial que un tribunal, como el TEDH, reconociera la existencia de un derecho inexistente en el CEDH e impusiera obligaciones positivas a los Estados parte.

Literalmente, tal derecho no es reconocible en ningún pasaje del $\mathrm{CEDH}$, tan solo cabría su reconocimiento vía interpretación de alguno de los preceptos que integran el texto europeo o sus protocolos. Por ello, se ha demandado asiduamente que «la libertad de recibir o comunicar informaciones» del art. 10.1 CEDH sea interpretada de manera que se incluya un «derecho a buscar informaciones», como se debatió durante los trabajos preparatorios del CEDH y de su Protocolo n. ${ }^{\circ}$ 6, o como sí hacen otros textos internacionales.

En esta labor de interpretación el TEDH ha tenido en cuenta varios criterios hermenéuticos, contenidos en los arts. 31-33 del Convenio de Viena sobre los Tratados, como el sentido corriente de los términos utilizados en el texto y los trabajos preparatorios del CEDH.

La primera redacción realizada por el Comité de Expertos del borrador preliminar del CEDH, en 1950 era idéntica al art. 19 de la Declaración Universal de Derechos Humanos $^{6}$ y por tanto contenía el derecho a buscar información. No obstante, la palabra «buscar» se quitó de la redacción final sin ningún tipo de discusión ${ }^{7}$. Por ello, el TEDH ha entendido que de los trabajos preparatorios no se puede deducir que hubiera un derecho de acceso a la información pública en el art. 10.1 CEDH. Sin embargo, el TEDH ha señalado que la historia de la redacción del Protocolo n. ${ }^{\circ} 6$ al CEDH revela un entendimiento común entre órganos e instituciones del Consejo de Europa de que el art. 10.1 $\mathrm{CEDH}$, en su redacción originariamente redactada, podría considerarse como razonable que comprendiera la «libertad de buscar información», aunque excluyendo la obligación de la autoridad pública a proporcionarla ${ }^{8}$.

Además, a juicio del TEDH, del sentido corriente de las palabras empleadas en el art. 10.1 CEDH, «la libertad de recibir o de comunicar informaciones», tampoco puede descartarse bajo determinas circunstancias que pudiera entenderse amparado el derecho de acceso a la información pública en el objeto o en el propósito del art. $10.1 \mathrm{CEDH}^{9}$.

Por último, el derecho a buscar información está reconocido en diferentes instrumentos internacionales de diferentes ámbitos, empezando por los arts. 19 de la Declaración Universal de Derechos Humanos y 19.2 del Pacto Internacional de Derechos Civiles y

6 Art. 19 de la DUDH: «Todo el mundo tiene derecho a la libertad de opinión y expresión; este derecho incluye el derecho a mantener opiniones sin interferencias, a buscar, recibir o difundir información e ideas a través de cualquier medio de comunicación sin importar las fronteras»

$7 \mathrm{La}$ inexistencia de la palabra «buscar» en el art. 10.1 CEDH constituye una gran diferencia con el art. 13 de la Convención Americana sobre Derechos Humanos de 1969 que sí lo incluye. De manera consecuente, el alcance de la paradigmática decisión de la Corte Interamericana Claude Reyes c. Chile, de 19 de septiembre de 2006 en cuanto a un pretendido derecho de acceso a la información es muchísimo mayor que la jurisprudencia del TEDH que se estudiará en las próximas páginas.

8 STEDH de Magyar Helsinki Bizottság c. Hungría, párrafo 124, párrafos 134-137.

9 STEDH de Magyar Helsinki Bizottság c. Hungría, párrafo 124, párrafos 135. 
Políticos ${ }^{10}$ que ha sido objeto de Observaciones ${ }^{11}$ y comunicaciones ${ }^{12}$ por parte del Comité de Derechos Humanos de Naciones Unidas incidiendo en ese sentido. También en la Carta de Derechos Fundamentales de la Unión Europea (CDFUE) se consagra explícitamente el «derecho a acceder a los documentos de las instituciones, órganos y organismos de la Unión, cualquiera que sea su soporte» (art. 42 CDFUE) $)^{13}$. Incluso en el marco del Consejo de Europa se ha reconocido este derecho, como la Recomendación de 21 de febrero de 2002 del Consejo de Ministros ${ }^{14}$, y de manera más explícita el Convenio del Consejo de Europa sobre Acceso a los Documentos Públicos, de 18 de junio de 2009, aún no en vigor. No podemos detenernos en el proceso de reconocimiento y consolidación de este derecho en el ámbito internacional ${ }^{15}$, pero el TEDH ha destacado que el CEDH es una norma internacional, y como tal ha de interpretarse como un todo, conforme a los citados arts. 31-33 del Convenio de Viena de 1968, persiguiendo una coherencia interna, teniendo en cuenta que las normas comunes internacionales o de derecho interno de los Estados europeos reflejan una realidad que el TEDH ha de tener en cuenta que deriva del consenso que

10 Art. 19.2 del PIDCP: «Toda persona tiene derecho a la libertad de expresión; este derecho comprende la libertad de buscar, recibir y difundir informaciones e ideas de toda índole, sin consideración de fronteras, ya sea oralmente, por escrito o en forma impresa o artística, o por cualquier otro procedimiento de su elección.»

11 El Comité de Derechos Humanos de NU ha considerado que «El párrafo 2 del artículo 19 enuncia un derecho de acceso a la información en poder de los organismos públicos. Esta información comprende los registros de que disponga el organismo público, independientemente de la forma en que esté almacenada la información, su fuente y la fecha de producción. Los organismos públicos son los indicados en el párrafo 7 de la presente observación general (esto es, todos los poderes del Estado, ejecutivo, legislativo y judicial, otras autoridades públicas o de gobierno, cualquiera que sea su nivel, nacional, regional o local y determinados actos de entidades semiestatales). La definición de esos organismos puede abarcar otras entidades que ejerzan funciones públicas.» Además, el Comité ha considerado que algunos elementos del derecho de acceder a la información se encuentran también en otras disposiciones del Pacto, como en el art. 17, señalando que «toda persona debe poder verificar qué autoridades públicas o qué particulares u organismos privados controlan o pueden controlar sus archivos» pudiendo solicitar su modificación. Observación General n. ${ }^{\circ} 34$, CCPR/C/GC/34, Artículo 19 PIDCP, Comité Derechos Humanos, Naciones Unidas, 12 de septiembre de 2011, párrafo 18.

12 Por ejemplo, Toktakunov v. Kyrgyzstan (Comunicación No. 1470/2006, 28 marzo de 2011), en donde el Comité considera que la información pública debe ser facilitada sin la necesidad de probar un interés directo o personal para obtenerlo, excepto en casos en los que pueda existir una causa de restricción prevista por la ley. Tampoco considera que la solicitud de esta información esté limitada a los medios de comunicación o a los periodistas profesionales, sino que pueden ser ejercidos por asociaciones privadas o individuos privados.

13 Con anterioridad a la Carta véase PeErs, S., «The new regulation on access to documents: a critical analysis», Yearbook of European law, n. 21, 2002, pp. 385 y ss; ARAI-TAKAHASHI, Y., «Scrupulous but dynamic: the freedom of expression and the principle of proportionality under European Community law», Yearbook of European law, n. 24, 2005, pp. 53-69. De especial importancia es la sentencia del Tribunal de Primera Instancia de la Unión Europea, asunto Heide Hautala contra Consejo de la Unión Europea, de 19 de julio de 1999, que consagró el derecho de acceso a la información en manos de las autoridades públicas. Para el Tribunal de Justicia, la interpretación del Consejo de la Unión Europea de denegar el acceso a los documentos «tendría el efecto de menoscabar, sin la menor justificación, el derecho de acceso del público a los elementos de información contenidos en un documento que no estén amparados por alguna de las excepciones enumeradas en el art. 4.1 de la Decisión 93/731», además, «la denegación de acceso parcial constituye ciertamente una medida manifiestamente desproporcionada para garantizar la confidencialidad de los elementos de información a los que sea de aplicación alguna de dichas excepciones», disponible en http://curia.europa.eu. Véase también el Reglamento (CE) n. ${ }^{\circ}$ 1049/2001 del Parlamento Europeo y del Consejo sobre el acceso del público a los documentos de las instituciones de la Unión Europea.

14 Recommendation $\operatorname{Rec}(2002) 2$ of the Committee of Ministers to the member States on Access to Official Documents, de 21 de febrero de 2002.

15 Para ello, véase el completo trabajo de Cotino Hueso, L., «El reconocimiento y contenido internacional del acceso a la información pública como derecho fundamental», Teoría y Realidad Constitucional, n. 40, 2017, pp. 279-316. 
surge de los instrumentos internacionales especializados y de la práctica de los Estados contratantes. ${ }^{16}$

Por estas razones expuestas, el TEDH ha considerado que, en ciertos tipos de situaciones y sujeto a condiciones específicas, puede haber argumentos de peso a favor de la lectura en el art. 10.1 CEDH de un derecho individual de acceso a información pública, y una obligación para el Estado de proporcionar dicha información. Negarlo daría lugar a situaciones en las que la libertad de «recibir e impartir» información se vería afectada de tal manera que afectaría la esencia misma de la libertad de expresión».

Sin embargo, una cosa es interpretar un determinado significado de un precepto concreto y otro «legislar» un derecho humano ex novo. En consecuencia, el TEDH solo reconoce este derecho de acceso a la información pública como un derecho instrumental, no como un derecho autónomo. Esto quiere decir que el TEDH solo reconocerá el derecho de acceso a la información pública en unas determinadas circunstancias en las que el acceso a la información sea un medio o herramienta para el ejercicio del derecho del solicitante a «recibir y difundir información». En consecuencia, la denegación del reconocimiento de ese derecho supondría una interferencia en el disfrute de ese derecho. En definitiva, para el TEDH «el principio de garantizar los derechos del Convenio de manera práctica y efectiva requiere que el solicitante en una situación de ese tipo pueda contar con la protección del artículo $10 \mathrm{CEDH}{ }^{17}$. Con esta interpretación, el TEDH salvaría las reticencias de los Estados parte que han mostrado reiteradamente a considerar la existencia autónoma y ex novo de un derecho con tanto potencial y trascendencia como el de acceso a la información pública ${ }^{18}$.

El reconocimiento explícito en el ámbito del art. 10.1 CEDH y la aclaración de limitar el derecho de acceso a la información a su carácter instrumental lo ha realizado el TEDH en la trascendental sentencia de Gran Sala Magyar Helsinki Bizottság c. Hungría de 6 de noviembre de 2016. Sin duda, es una sentencia importantísima porque sintetiza y aclara la discusión sobre la eventual existencia, naturaleza jurídica y efectos de este derecho en la jurisprudencia del Tribunal de Estrasburgo. Sin embargo, desde nuestro punto de vista, esta decisión no agota la discusión sobre el derecho de acceso a la información, sino solamente sobre su interpretación en el seno del art. 10.1 CEDH. Dicho derecho de acceso, también podría estar presente, limitado además a su carácter instrumental, en otros ámbitos del CEDH, como el art. $8 \mathrm{CEDH}$ y el art. 6.1 CEDH.

\section{EL DERECHO DE ACCESO A LA INFORMACIÓN PÚBLICA COMO INSTRUMENTO PARA LA EFICACIA DE OTROS DERECHOS}

El derecho de acceso a la información pública se ha debatido y demandado principalmente en el ámbito del art. 10.1 CEDH y la libertad de expresión. Pero eso no quiere decir que sea un ámbito exclusivo, al menos no en la jurisprudencia del TEDH de los últimos años. Es importante tener en cuenta que este derecho objeto de nuestro

16 STEDH Magyar Helsinki Bizottság c. Hungría, párrafo 124.

17 STEDH Magyar Helsinki Bizottság c. Hungría, párrafo 155.

18 Véase, por todos, los argumentos en contra de Hungría y del Reino Unido en la STEDH de Magyar Helsinki Bizottság c. Hungría, párrafos 67, 73-81 y 99-100, respectivamente. 
estudio también despliega su carácter instrumental para contribuir a la garantía de otros derechos. De hecho, en una primera época a la que se hará referencia, el TEDH reconoció este derecho más claramente en el ámbito del art. $8 \mathrm{CEDH}$ y su importancia para contribuir a proteger el derecho a la vida privada y familiar. También es de interés tener en cuenta la labor que podría jugar en ciertas circunstancias para la eficacia de la tutela judicial efectiva (art. 6.1 CEDH). Y debido a que el CEDH se ha centrado en derechos civiles y no políticos, el derecho de acceso a la información pública no ha podido desplegar sus efectos en un ámbito donde tiene, sin lugar a dudas, un grandísimo potencial: la participación política del ciudadano. El derecho a elecciones libres del art. 3 del Protocolo $1 \mathrm{CEDH}$ es tan solo una pequeña porción de un derecho que vertebra cualquier sistema político democrático y del que depende, entre otros muchos factores, su calidad, resultando a todas luces insuficientes para hacer efectivo un «régimen político verdaderamente democrático» al que hace referencia el Preámbulo del CEDH.

\section{Concepto tradicional. Exclusión del art. $10 \mathrm{CEDH}$ y obligación positiva de acceso en el art. $8 \mathrm{CEDH}$ bajo determinadas circunstancias}

Desde el principio, el art. 10 del $\mathrm{CEDH}$ no fue interpretado de una manera que otorgara a los ciudadanos un derecho de acceso a la información en posesión del Estado, pues el TEDH rechazó de manera sistemática pronunciarse sobre el derecho de acceso a documentos o el derecho a solicitar activamente información dentro del art. 10 CEDH.

En un contexto específico de acceso a la información, el TEDH mantuvo una interpretación muy liberal y sostuvo tradicionalmente que el derecho a recibir una información se refería al acceso a fuentes de información generales y consistía básicamente en prohibir al Gobierno que impidiera u obstaculizase a una persona recibir información de otras personas que desearan o quisieran dársela. De la misma manera, el Tribunal de Estrasburgo nunca aceptó que el art. $10 \mathrm{CEDH}$ estableciera un derecho de acceso a un registro que contuviera información de su posición personal, ni tampoco que impusiera una obligación positiva ${ }^{19}$ al Estado de recabar y difundir esa información al individuo. En definitiva, el TEDH no deducía del CEDH un derecho general de acceso a documentos y datos administrativos ${ }^{20}$.

No obstante, en lugar de centrarse en el art. $10 \mathrm{CEDH}$, bajo ciertas circunstancias permitió excepciones sobre el acceso a la información cuando otros derechos fundamentales se vieran afectados, como el derecho al respeto a la vida privada y a la vida familiar del art. 8 CEDH.

Esta es la postura que el TEDH mantuvo a lo largo de los primeros años de su jurisprudencia sobre el tema. Para comprenderla es necesario atender a tres casos capitales:

19 Sobre la problemática de las obligaciones positivas a los Estados bajo el CEDH véase Xenos, D., The Positive Obligations of the State under the European Convention of Human Rights, Routledge, 2012. Concretamente, sobre las obligaciones positivas en el marco del art. $10 \mathrm{CEDH}$ véanse, Mowbray, A., The Development of Positive Obligations under the European Convention on Human Rights by the European Court of Human Rights, Hart Publishing, 2004, pp. 191195; Dijk, P. van, Hoof, F. van, Rijn, A. van y ZwaAk, L. (eds), Theory and Practice of the European Convention on Human Rights, Intersentia, 4th ed., 2006, pp. 784-788.

20 Por todas, véase STEDH Loiseau c. Francia, 28 de septiembre de 2004 (decisión). 
Leander c. Suecia ${ }^{21}$, Gaskin c. Reino Unido ${ }^{22}$ y Guerra y otros c. Italia ${ }^{23}$, jurisprudencia recopilada posteriormente por la Gran Sala en Roche c. Reino Unido $0^{24}$. Estos casos muestran como, al contrario de la Declaración Universal de Derechos Humanos y del Pacto Internacional de Derechos Civiles y Políticos, el art. 10 CEDH no ampara el derecho a solicitar información. Solo cubre el derecho a recibir información de fuentes de información general o un derecho de acceso a fuentes generales de información. Sin embargo, el TEDH admitió demandas sobre la libertad de recibir información sobre la base del art. $8 \mathrm{CEDH}$, tutelando el derecho al respeto por la vida privada y la vida familiar.

En Leander c. Suecia, de 26 de marzo de 1987, el TEDH solventa la demanda de un ciudadano sueco cuya solicitud de puesto de trabajo en un museo naval con instalaciones próximas a una base naval del ejército es rechazada. Este puesto de trabajo requería acceder a zonas del museo restringidas por motivos de seguridad nacional. El rechazo se produjo tras la consulta por parte de las autoridades de la Armada de un expediente secreto sobre la vida privada del demandante elaborado por la policía de seguridad sueca. Este expediente tan solo hacía referencia a la pertenencia del demandante al partido comunista sueco y a una asociación que publicaba una revista radical. Las autoridades suecas le negaron el acceso a este expediente secreto, que contenía información relacionada con su vida privada, por lo que reclamó la violación de sus derechos a la vida privada (art. 8 $\mathrm{CEDH}$ ) y a recibir información (art. 10.1 CEDH). El TEDH rechazó que se hubiera violado ninguno de los dos derechos. En cuanto a la vida privada, el TEDH consideró que la injerencia de los poderes públicos que suponía almacenar y divulgar su vida privada, y no poder refutarla, estaba justificada en aras de la protección de la seguridad nacional sin ser desproporcionada ${ }^{25}$. En relación con el derecho a recibir información, el TEDH adoptó un enfoque liberal, limitándose a sentenciar que el derecho a recibir información reconocido en el art. 10.1 CEDH se limita a «probibir a un gobierno restringir la información que una persona pueda recibir de otra que quiera o quisiera difundir». De la misma manera, este derecho, en las circunstancias actuales de ese caso, «no confiere un derecho a los particulares de acceso a los registros o archivos que contengan información sobre una situación personal, ni tampoco impone una obligación a los gobiernos de difundir la información solicitada por los particulares» ${ }^{26}$. Podría deducirse, ad sensu contrario, que el derecho a recibir información se aplicaba solo a la información que el poseedor de la misma quisiera difundir.

La misma interpretación del art. 10.1 CEDH fue mantenida por el TEDH en pleno en Gaskin c. Reino Unido dos años después ${ }^{27}$. El demandante, Graham Gaskin desde la muerte de su madre siendo menor de edad fue atendido por los Servicios Sociales de Liverpool y acogido por diferentes familias. Tras su mayoría de edad quiso tomar acciones legales contra dichos Servicios Sociales locales, pues en su opinión el trato dispensado no había sido el adecuado. Para poder plantear las demandas solicitó todos los expedientes e información sobre sus procesos de acogida, pero su solicitud fue rechazada por ser

21 STEDH Leander c. Suecia, 26 de marzo de 1987.

22 STEDH Gaskin c. Reino Unido, 7 de julio de 1989.

23 STEDH Guerra y otros c. Italia, 19 de febrero de 1998.

24 STEDH Roche c. Reino Unido, 19 de octubre de 2005.

25 STEDH Leander c. Suecia, párrafos 49-68.

26 STEDH Leander c. Suecia, 26 de marzo de 1987, párrafo 74.

27 STEDH Gaskin c. Reino Unido, 7 de julio de 1989. 
contraria al interés público, pues con la revelación de toda esa información perjudicaría la estricta confidencialidad de las actuaciones y personas que colaboran con esos servicios, desde médicos, hasta trabajadores sociales, profesores, policías, etc. El TEDH interpretó que la demanda del Sr. Gaskin estaba relacionada con su derecho a la vida privada y familiar (art. $8 \mathrm{CEDH}$ ) y que, por tanto, el acceso a esa documentación debía examinarse a la luz de este derecho. Además, el TEDH fue claro al sentenciar que ese planteamiento se tomó «sin expresar ninguna opinión sobre si del art. $8 \mathrm{CEDH}$ podría derivar un derecho de acceso general a los datos personales e información personal». ${ }^{28}$ Por otra parte, el TEDH hizo notar que la información solicitada por el Sr. Gaskin era diferente a la del Sr. Leander del caso anterior, pues en el presente caso la información personal contenida no era el objeto principal de solicitud ni de los documentos solicitados, ni tampoco su almacenamiento o tratamiento. En realidad, la queja del demandante no se refería a la interferencia en su vida privada por haber elaborado expedientes sobre su persona como en Leander, y no poder acceder a los mismos, sino a una interferencia por no facilitar esos expedientes que contienen su vida personal. Por eso, el TEDH examinó el caso desde la perspectiva de juzgar si el Reino Unido, al manejar la solicitud de acceso a su expediente, vulneraba o no una obligación positiva del Estado que pudiera derivarse del art. 8 CEDH. ${ }^{29}$ El Tribunal de Estrasburgo estimó que el sistema del Reino Unido, para determinar si se facilitaba o no la información solicitada, se basaba en el consentimiento de las personas afectadas por esa revelación, esto es, de los colaboradores con el sistema asistencial de menores. Sin embargo, en caso de que los colaboradores no contestaran o no dieran su consentimiento, no se establecía una autoridad independiente que resolviera finalmente esa cuestión. La existencia de esta autoridad es exigida por el principio de proporcionalidad y a diferencia con el caso Leander, no existía en el país demandado. Por ello, el TEDH sentenció que se vulneró el art. $8 \mathrm{CEDH}$ estableciendo la obligación positiva sobre el Estado de incorporar esa garantía para ese procedimiento. ${ }^{30} \mathrm{La}$ injerencia desproporcionada prohibida por el art. 8.2 CEDH en realidad impedía el acceso a una serie de documentos que afectaban a la vida privada del demandante, subyaciendo por tanto el carácter instrumental de dicho acceso para la eficacia del art. $8 \mathrm{CEDH}$. Respecto del art. 10.1 CEDH, el TEDH reprodujo, palabra por palabra, lo expresando en Leander sobre la obligación del Estado de no restringir comunicaciones y la negación de una obligación a informar por parte de la autoridad que ostentara la información solicitada. ${ }^{31}$

En el caso Guerra y otros contra Italia ${ }^{32}$, cuarenta ciudadanos italianos demandaron a su Estado por no facilitar información suficiente sobre una planta de productos químicos situada cerca de su población y cuyas actividades podrían ser peligrosas para su salud y sus vidas. El TEDH enjuició la negativa a dar esa información desde el art. $8 \mathrm{CEDH}^{33}$. Por tanto, desde esta doctrina, el TEDH sostuvo que el art. 8 CEDH imponía a las autoridades

28 STEDH Gaskin c. Reino Unido, párrafo 37.

29 STEDH Gaskin c. Reino Unido, párrafo 41.

30 STEDH Gaskin c. Reino Unido, párrafo 41

31 STEDH Gaskin c. Reino Unido, párrafo 52

32 STEDH Guerra y otros c. Italia, 19 de febrero de 1998

33 Porque para garantizar la protección a la vida privada y familiar pueden presuponerse obligaciones positivas inherentes. Véase, por ejemplo, STEDH Airey c. Irlanda, 9 de octubre de 1979, párrafo 32. Además, las autoridades nacionales han de tomar las medidas necesarias para asegurar la protección efectiva de los derechos de los demandantes para respetar su vida privada y familiar. Véase, por ejemplo, STEDH López Ostra c. España, 9 de diciembre de 1994, párrafo 55. 
estatales una obligación positiva de informar a las personas que vivían cerca de la fábrica sobre el riesgo de potenciales accidentes devastadores. En caso de no cumplir con esta obligación, se dejaba a esas personas sin la posibilidad de valorar los riesgos y por tanto sin la posibilidad de tomar decisiones informadas sobre vivir en las proximidades de instalaciones peligrosas. En consecuencia, el TEDH sentenció que el Estado italiano no tomó las medidas suficientes para cumplir su obligación de garantizar su derecho a la vida privada y familiar, vulnerando por tanto el art. $8 \mathrm{CEDH}^{34}$. A pesar de esta falta de información, el TEDH sostuvo que el art. $10 \mathrm{CEDH}$ no era aplicable ${ }^{35}$ y mantuvo la misma línea que en Leander y Gaskin respecto del art. 10.1 $\mathrm{CEDH}^{36}$. Sin embargo, en el fondo, el resultado de esta decisión del TEDH fue reconocer un derecho a recibir información, bajo ciertas circunstancias, pero meramente de fuentes generales de información.

En 2005 la Gran Sala recopiló la doctrina de las tres sentencias estudiadas en el caso Roche c. Reino Unido, 19 de octubre de 2005, donde un antiguo soldado británico aquejado de varias dolencias solicitó los informes médicos que le realizaron cuando estuvo en contacto con ensayos de productos químicos. El TEDH sentenció que el Estado había violado el art. 8 $\mathrm{CEDH}$ por no haber facilitado toda la información que necesitaba para evaluar los riesgos de su estado de salud que pudiera resultar de la participación en dichas pruebas militares, pues pesaba sobre el Estado una obligación positiva de procurar un procedimiento efectivo y accesible que le permitiera acceder a toda esa información relevante y necesaria. ${ }^{37}$ Sin embargo, respecto del art. $10 \mathrm{CEDH}$, el TEDH sostuvo su postura expresada en Leander, Gaskin y Guerra, dejando claro que no veía «ninguna razón para no aplicar esta consolidada jurisprudencia» sobre no imponer a un Estado en las circunstancias de este caso, «las obligaciones positivas para reunir y difundir, por su propia iniciativa, la información» ${ }^{38}$.

Roche c. Reino Unido es muy similar a otro caso sustanciado por el TEDH cinco años antes. En McGinley y Egan c. Reino Unido, 28 de enero de 2000, dos ciudadanos británicos que habían estado presentes como militares en ambientes de ensayos nucleares se quejaban, entre otras cosas, de que la falta de acceso a los registros de realización de dichas pruebas constituía un vulneración de su vida privada y familiar en el marco de sus solicitudes de pensiones de invalidez. El TEDH consideró que, bajo el art. $8 \mathrm{CEDH}$, el Estado tenía la obligación positiva de dar acceso al material interesado por los demandantes pues no había ningún perjuicio contra el interés público si se revelaba ${ }^{39}$. En este caso, el TEDH no determinó la violación del art. $8 \mathrm{CEDH}$ debido a que ninguno de los solicitantes optaron por acogerse a un procedimiento que el Estado tenía establecido, asociado a su proceso de reclamación de la pensión, por el que podían haber solicitado a las autoridades competentes información al respecto. Sin embargo optaron por solicitar la información por otras vías. ${ }^{40}$

34 STEDH Guerra y otros c. Italia, párrafos 58-60.

35 STEDH Guerra y otros c. Italia, párrafo 54.

36 STEDH Guerra y otros c. Italia, párrafo 53. Es interesante destacar que la Comisión sostuvo exactamente lo contrario, en el sentido de que el art. 10.1 CEDH reconocía un deber de facilitar información a la ciudadanía, así como una obligación positiva para recabar, procesar y difundir la información solicitada, que no podría llegar a la ciudadanía de otra forma, Guerra y otros c. Italia, párrafo 52. En la misma línea se pronunciaron dos magistrados que redactaron votos particulares disidentes.

37 STEDH Roche c. Reino Unido, 19 de octubre de 2005, párrafo 167.

38 STEDH Roche c. Reino Unido, 19 de octubre de 2005, párrafo 172.

39 STEDH McGinley y Egan c. Reino Unido, párrafo 101.

40 STEDH McGinley y Egan c. Reino Unido, párrafo 89 y 101. 
El estudio de estos casos permite concluir que en esta primera etapa el TEDH aceptó, bajo ciertas circunstancias, reconocer un derecho de acceso a algunos documentos que aunque no fueran generalmente accesibles, fueran de particular importancia para la situación concreta del demandante, ya se refiriera a la protección medioambiental, a la salud pública o al bienestar individual. Este reconocimiento fue deducido del derecho a la vida privada y vida familiar (art. $8 \mathrm{CEDH}$ ) y no del derecho a la libertad de recibir información (art. 10.1 CEDH). El TEDH entendió que, bajo ciertas circunstancias, puede surgir una obligación positiva del Estado de tener a disposición de los ciudadanos un procedimiento o mecanismo por el cual pudieran solicitar información de su incumbencia, máxime cuando la revelación de esta información no supusiera un peligro o inconveniente para los intereses públicos, y esa información fuera de importancia para intereses como la salud de los demandantes.

Sin embargo, el TEDH no consideró que el art. 10 CEDH fuera de aplicación en los casos estudiados, insistiendo en su postura inamovible de que la libertad de recibir información a la que se refiere el art. 10.1 CEDH tan solo prohíbe a un gobierno restringir la recepción de información a una persona que otros deseen o pueda querer transmitirles, sin que pueda ser interpretada como una obligación positiva al Estado de recabar y transmitir información de oficio. Durante esta época, el TEDH mantuvo su postura liberal de manera inamovible y no modificó su doctrina señalada en Sunday Times c. Reino Unido, donde estableció que el art. $10 \mathrm{CEDH}$ se limitaba a garantiza el derecho de los ciudadanos a ser informados adecuadamente ${ }^{41}$, incluyendo este derecho a buscar información de fuentes generales de información. Por tanto, incluso si el Estado no tenía la obligación de facilitar una información determinada, en principio, esa información no debería ser denegada cuando fuera de interés general, pero sin incluir obligaciones positivas, y en particular, una obligación de facilitar el acceso a la información al amparo del art. 10 CEDH.

\section{Paso de transición. Hacia un reconocimiento del derecho de acceso dentro del art. $10 \mathrm{CEDH}$}

El 19 de julio de 2006 la Sección quinta del TEDH dictó una decisión de inadmisión, Sdružení Jibočeské Matky c. República Checa ${ }^{42}$, que estableció un punto de inflexión en la interpretación del derecho de acceso a la información respecto del art. $10 \mathrm{CEDH}$, separándose de la línea constante marcada en los casos Leander, Gaskin, Guerra y Roche. Por primera vez, el TEDH concibe el derecho de acceso a una información relevante en el ámbito del art. $10 \mathrm{CEDH}$ y no en el del art. $8 \mathrm{CEDH}$ como había venido haciendo. De hecho, el mismo TEDH afirmó en una decisión posterior sobre esta decisión que «el Tribunal ha avanzado recientemente hacia una interpretación más amplia de la noción «libertad a recibir información» y por tanto hacia el reconocimiento de un derecho de acceso a la información». ${ }^{43}$

Sdružení Jihočeské Matky es una ONG checa fundada por personas que vivían cerca de la central nuclear de Temelin de titularidad estatal, cuyas tareas principales son la

41 STEDH Sunday Times c. Reino Unido (No I), 26 de abril de 1979, párrafo 66.

42 STEDH Sdružení Jibočeské Matky c. República Checa, de 19 de julio de 2006 (decisión).

43 STEDH Társaság a Szabadságjogokért c. Hungría, 14 de abril de 2009, párrafo 35. 
protección de la naturaleza y medio ambiente y contraria a tecnologías como la energía nuclear. A raíz de la entrada en vigor de una ley estatal de protección de naturaleza y paisaje que concedía el derecho a los ciudadanos a ser informados por las autoridades y a participar en todos los procedimientos administrativos que pudieran afectar a los intereses de protección de la naturaleza y el paisaje, dicha ONG presentó una solicitud para que le mantuviera informada de los procedimientos relativos a la central nuclear de Temelin. Sin embargo, solo se le autorizó a participar y conocer de un procedimiento, concretamente sobre cambios tecnológicos en la construcción de una parte del edificio. Los tribunales nacionales, incluido el Tribunal Constitucional no estimaron vulnerado el derecho a la información, reconocido en el art. 17.4 Constitución de la República Checa, por considerar la restricción proporcionada y necesaria en una sociedad democrática. En consecuencia, la ONG se quejó de que las autoridades nacionales, al denegarle el acceso a parte de la documentación de la planta de energía nuclear violaron su derecho a recibir información reconocido en el art. 10 CEDH. El TEDH, en las circunstancias concretas del caso, admitió que el rechazo de la solicitud constituía una injerencia en el derecho del demandante a recibir información ${ }^{44}$. Sin embargo, esta injerencia estaba plenamente justificada ya que la solicitud se realizaba sobre información de una planta de energía nuclear, que es un sistema de gran complejidad y que exige un nivel muy alto de seguridad. Por tant0o, el TEDH consideró que el art. $10 \mathrm{CEDH}$ no podía interpretarse como una garantía del derecho absoluto de acceso a todos los detalles técnicos relacionados con la construcción de una planta, ya que, a diferencia de la información sobre el impacto ambiental de los mismos, tales datos no podían considerarse de interés público, por lo que la negativa estaría justificada por motivos de seguridad nacional, salud pública y secreto industrial. ${ }^{45}$

Por tanto, por primera vez, el TEDH sitúa en el ámbito del art. $10 \mathrm{CEDH}$ una solicitud de información con relevancia pública y ni siquiera menciona la obligación positiva que pudiera pesar sobre el Estado fruto del art. $8 \mathrm{CEDH}$.

De esta manera, y puntualizando la importancia de las circunstancias concretas del caso, el TEDH admitió que el rechazo de la solicitud de información de relevancia pública constituía una injerencia en el derecho del demandante a recibir información, dando el primer paso para un eventual reconocimiento de este derecho en la jurisprudencia del TEDH en el ámbito del art. 10.1 CEDH. Sin embargo, también enfatizó que era «difícil deducir del CEDH un derecho de acceso general de acceso a los datos y documentos de una naturaleza administrativa».

\section{Reconocimiento del derecho de acceso a la información pública en el ámbito del art. $10 \mathrm{CEDH}$}

Desde el 2009 hasta la actualidad, el TEDH ha dictado una serie de resoluciones en las que abiertamente hace referencia al derecho de acceso a la información como parte del art. 10 CEDH. Társaság a Szabadságjogokért c. Hungría, de 14 de abril de 2009, ha supuesto la primera de las sentencias que abogan claramente por esta interpretación, sobre todo debido al tipo de información solicitada. Esta postura ha sido confirmada por

44 STEDH Sdružení Jibočeské Matky c. República Checa, párrafo 1.1.

45 STEDH Sdružení Jibočeské Matky, párrafo 1.1. 
otras 5 decisiones, todas ellas de Secciones, que establecen una línea jurisprudencial clara sobre la materia, y finalmente por una decisión de la Gran Sala, Magyar Helsinki Bizottság c. Hungría, de 8 de noviembre de 2016, que consagra esta interpretación bajo las condiciones y circunstancias que en ella se explicitan.

En Társaság a Szabadságjogokért c. Hungría, de 14 de abril de 2009, la Unión Húngara de Libertades Civiles demandó ante los tribunales la negativa del Tribunal Constitucional húngaro de permitirle acceder a la demanda planteada por un parlamentario sobre la constitucionalidad de unas modificaciones recientes al Código Penal, concretamente en relación con delitos relacionados con drogas. El Tribunal Constitucional rechazó la solicitud al considerar que el demandante no tenía derecho a solicitar esa información pues no consideraba que fueran «datos» y por tanto no encajaba en la Ley de Datos húngara de 1992 sobre la que la demandante basaba su pretensión de acceso a la información. En esta sentencia la Sección Segunda del TEDH, a pesar de seguir negando el derecho de las personas a acceder a un expediente con información personal, ni la obligación del Estado de facilitar esa información al solicitante ${ }^{46}$, ni el derecho general de acceso a los datos y documentos administrativos ${ }^{47}$, confirma su postura de insistir en una interpretación más amplia de la noción de «libertad a recibir información» ${ }^{48}$ y por tanto reconociendo de cierta manera el derecho de acceso a la información pública.

Para ello, el TEDH reconoció el importante papel que las ONGs, cuya labor incide en el fomento de los derechos humanos como la libertad de información, tienen para fomentar un debate público informado para la ciudadanía ${ }^{49}$. En consecuencia, el TEDH estima en esta sentencia que estas organizaciones deberían gozar de los mismos niveles de protección que la prensa, pues las considera igualmente "perros guardianes de la sociedad» (social watchdogs).$^{50}$ En este caso concreto, es claro para el TEDH que la materia solicitada al Tribunal Constitucional, esto es, el contenido de la demanda de constitucionalidad contra una ley penal, es una materia de interés público y no podía aceptarse lo alegado por el Estado húngaro de que del recurso podrían derivarse datos personales privados del parlamentario que de permitirse el acceso serían revelados sin permiso. ${ }^{51}$ La organización demandante se dedicaba a recabar información sobre este tipo de cuestiones, por lo que la negativa del Tribunal Constitucional húngaro constituyó un obstáculo. En este sentido, y dado que el Alto Tribunal Húngaro ostentaba el monopolio de la información, el TEDH consideró que esta actitud constituyó un tipo de censura. ${ }^{52}$ Para determinar la legitimidad o no de esta injerencia en el derecho a recibir información de la organización demandante, el TEDH partió de recordar que los Estados tienen la obligación de no

46 Siguiendo la jurisprudencia de Leander, Gaskin, Guerra y Roche.

47 Loiseau c. Francia, 28 de septiembre de 2004 (decisión).

48 Como ya hiciera en Sdružení Jibočeské Matky contra la República Checa.

49 El TEDH ha reconocido de manera constante la importante contribución de la sociedad civil a la discusión de los asuntos públicos. Véase, por ejemplo STEDH Steel and Morris c. Reino Unido, 15 de febrero de 2005, párrafo 89; STEDH Vides Aizsardzibas Klubs c. Lituania, 27 de mayo de 2004, párrafo 42; STEDH Riolo c. Italia, de 17 de julio de 2008, párrafo 63.

50 STEDH Társaság a Szabadságjogokért c. Hungría, párrafo 27. Véase también STEDH Animal Defenders International c. Reino Unido (GC), 22 de abril de 2013, párrafo 103; STEDH Thorgeir Thorgeirson c. Islandia, 25 de junio de 1992, párrafo 63; STEDH Jersild v. Denmark, 23 de septiembre de 1994, párrafo 35; STEDH Vides Aizsardzibas Klubs c. Lituania, 27 de mayo de 2004, párrafo 42.

51 STEDH Társaság a Szabadságjogokért c. Hungría, párrafos 28 y 37.

52 STEDH Társaság a Szabadságjogokért c. Hungría, párrafo 28. 
impedir el flujo de información relevante buscado o solicitado por el demandante, máxime cuando una autoridad estatal ostenta el monopolio de una información. En este caso es incluso más obvio que se incurrió en este comportamiento, pues la información que se solicitaba no tenía que ser objeto de preparación ni implicaba ningún tipo de trabajo, sino que ya estaba disponible y podía ser entregada sin problemas. Como ya se apuntó, cuando se da esta situación de monopolio informativo, la jurisprudencia del TEDH impone la obligación de seguir el escrutinio más cuidadoso para no interferir con el tráfico informativo. ${ }^{53}$

Por todo ello, el TEDH consideró que los obstáculos creados para obstaculizar el acceso a la información de interés público podrían repercutir negativamente en el trabajo de esta organización, o de los medios de comunicación, en su intención de investigar esas cuestiones relevantes y contrastadas para la sociedad, por lo que sentenció la violación del derecho de acceso a la información (art. $10 \mathrm{CEDH})^{54}$.

Ese mismo año, la misma Sección Segunda del TEDH se pronunció sobre la solicitud de un historiador de acceder a documentos del Ministerio del Interior para escribir un estudio sobre el funcionamiento de los Servicios de Seguridad del Estado de Hungría en los años 60. El demandante, János Kenedi, es un historiador especialista en el funcionamiento de los servicios secretos en dictaduras y de las fuerzas políticas policiales de los regímenes totalitarios y el funcionamiento de los Estados soviéticos, y ha publicado varios trabajos sobre la materia. Ante la negativa del Ministerio, los tribunales húngaros le dieron la razón para que pudiera acceder a todos los documentos solicitados, pero el Ministerio no le entregó la documentación que consideró protegida por secreto de Estado. Esta negativa ocasionó otro largo y tedioso procedimiento judicial tras el cual el Ministerio no entregó los documentos que consideró peligroso para la seguridad nacional, a pesar de las sentencias judiciales en contrario.

En la sentencia Kenedi c. Hungría, de 26 de mayo de 2009, el TEDH destacós5 que el «acceso a las fuentes documentales originales para una investigación histórica legítima era un elemento esencial del ejercicio del derecho a la libertad de expresión del demandante». ${ }^{56}$ Además, dada la evidente oposición del gobierno húngaro a hacer efectivas las sentencias de los tribunales nacionales, rayana en la arbitrariedad, no podía ser considerada como un comportamiento «prescrito por el Derecho» (art. 10.2 CEDH). Por todo ello, sentenció la vulneración del art. $10 \mathrm{CEDH} .{ }^{57}$

De nuevo la Sección Segunda del TEDH conoció la demanda planteada por la ONG Youth Initiative for Human Rights c. Serbia, de 25 de junio de 2013, con objeto de la solicitud realizada a la agencia de inteligencia de Serbia para que le informara de cuántas personas habían sido objeto de vigilancia electrónica por esa agencia durante el año 2005. Tras la negativa de la agencia de inteligencia, la Autoridad Protectora de Datos de Serbia le requirió que le diera acceso a la información solicitada en tres días, basándose para ello en la Ley serbia de Libertad de Información de 2004. Tras considerar que la agencia no

53 STEDH Társaság a Szabadságjogokért c. Hungría, párrafo 36. Véase, por ejemplo, STEDH Chauvy y otros $c$. Francia, 29 de junio de 2004, párrafo 66; STEDH Bladet Tromsø and Stensaas c. Noruega, [GC], 20 de mayo de 1999, párrafos 59 y 64 .

54 STEDH Társaság a Szabadságjogokért c. Hungría, párrafos 38 y 39.

55 Siguiendo la decisión de Társaság a Szabadságjogokért c. Hungría.

56 STEDH Kenedi c. Hungría, 26 de mayo de 2009, párrafo 43.

57 STEDH Kenedi c. Hungría, 26 de mayo de 2009, párrafo 45. 
tenía legitimidad activa, el Tribunal Supremo rechazó la apelación y por fin tres años después de la formulación de acceso la agencia contestó a la demandante que no tenía la información solicitada.

El TEDH continuó la línea iniciada en Társaság de considerar que de la noción «libertad de recibir información» se puede deducir un derecho de acceso a la información, insistiendo en el importante papel de «social public watchdog» de las organizaciones no gubernamentales implicadas en asuntos de interés público, similar al que realiza la prensa y merecedora por tanto de la misma protección. Como el objetivo de esa organización era recabar información y difundirla a la ciudadanía para contribuir al debate público, la negativa de la agencia de inteligencia supuso desde la perspectiva del TEDH una interferencia en el derecho a la libertad de expresión de la asociación. Además, debido a la obstinada desobediencia de la agencia de la decisión basada en Derecho de la Autoridad Protectora de Datos y que su respuesta final de no tener la información no era creíble, el Tribunal de Estrasburgo consideró que no respetaba la legalidad nacional y su actitud rayaba la arbitrariedad. Por ello consideró vulnerado el art. 10 ECHR. ${ }^{58}$

En esta sentencia es importante resaltar el voto particular firmado por dos magistrados, Sajó y Vučinić llamando la atención sobre la particular importancia del sentido de esta decisión para aquellos países donde, incluso hoy, persisten unos hábitos arraigados desde hace años que dificultan el acceso a los datos que, en los tiempos del totalitarismo, eran utilizados para propósitos opresivos por los servicios secretos ${ }^{59}$. Por ello, insistieron en destacar, a la vista de las demandas de las democracias en la actual sociedad de la información, tres aspectos trascendentales: en primer lugar, en el mundo de Internet, la diferencia entre periodistas y otros miembros de la ciudadanía están desapareciendo rápidamente ${ }^{60}$, por ello es evidente que sin transparencia, que debe ser usada y está al servicio de los ciudadanos, no puede existir una democracia robusta; en segundo lugar, los Estados son responsables de almacenar los datos controlados por los gobiernos, y su pérdida no es una excusa para no facilitarlos; en tercer lugar, no hay que establecer una distinción artificial entre los datos públicos y los datos de interés personal, pues una errónea diferenciación podría dificultar el derecho de acceso a la información pública.

En el caso Österreichische vereinigung zur erbaltung, stärkung und schaffung eines wirtschaftlich gesunden land- und forst-wirtschaftlichen grundbesitzes c. Austria, de 28 de noviembre de 2013 (en adelante Österreichische Vereinung... c. Austria) el TEDH también apreció la violación del art. $10 \mathrm{CEDH}$ pero hay importantes diferencias respecto de los tres casos anteriores que contribuyen a perfilar los contornos del derecho de acceso a la información. La Asociación Austríaca para la Preservación, Fortalecimiento y la Creación de una Prosperidad Económica en Fincas Agrícolas y Forestales, organización no gubernamental, tiene como objetivo investigar y estudiar las transferencias de propiedades agrícolas y forestales y sacar conclusiones sobre el impacto de dichas transferencias en la

58 STEDH Youth Initiative for Human Rights c. Serbia, párrafos 24-26.

59 Esta ha sido una denuncia constante, demandando más escrutinio sobre los países principalmente que han salido recientemente de experiencias dictatoriales. Véase, por ejemplo el voto particular del magistrado Sajó en STEDH Regner c. República Checa, de 26 de noviembre de 2015 y en STEDH Youth Initiative for Human Rights c. Serbia, 25 de junio de 2013 .

60 Véase al respecto, por ejemplo, STEDH Delphi AS c. Estonia, de 16 de junio de 2015. 
sociedad. También aporta opiniones a los proyectos de ley relativos a estos asuntos. Las trasferencias de propiedades agrícolas y forestales requieren la aprobación de las autoridades locales y regionales para evitar que la tierra se utilice para la construcción, y siga siendo de uso agrícola y forestal. La citada organización no gubernamental solicitó a una de las autoridades públicas citadas (concretamente la de la región del Tirol) información sobre todas las decisiones tomadas sobre las transferencias de propiedades desde el 1 de enero de 2000. La autoridad contestó no poder cumplir semejante solicitud, pues al no tener publicada ninguna resolución hasta el momento, no podría hacerlo dada la falta de tiempo y personal, y además, porque en su opinión lo solicitado no constituía información conforme a la Ley de Información austriaca. La ONG austríaca estimó que semejante negativa violaba su derecho a recibir información (art. $10 \mathrm{CEDH}$ ) alegando que este tipo de decisiones deberían ser accesibles públicamente. El Estado alegó que conforme al art. $10 \mathrm{CEDH}$ no puede imponerse una obligación positiva de recabar y difundir toda la información específica de todos los casos, aunque sí deben permitir un acceso de información general. Solo las partes con intereses legítimos podrían tener derecho a solicitar este tipo de información.

El TEDH volvió a insistir en la importancia de las organizaciones que actúan como «watchdogs» en las sociedades y en aumentar su tutela y el escrutinio a las prácticas que dificulten su actividad. ${ }^{61}$ Además, incidió de nuevo en que investigar y reunir información es una fase preparatoria esencial en el periodismo y parte protegida inherente de la libertad de prensa. ${ }^{62}$ Por tanto, la solicitud de la ONG austríaca entra dentro del derecho a recibir información relevante para la sociedad y la negativa de la autoridad estatal supuso una infracción de su derecho. Sin embargo, el TEDH insistió en que del art. 10 $\mathrm{CEDH}$ no se podía inferir una obligación general de acceso a toda la información. Como punto diferencial del resto de demandas estudiadas, el TEDH enfatizó que la ONG demandante no solicitó acceso a un documento particular, sino a todas las resoluciones dictadas durante una época larga de tiempo, sin ningún tipo de discriminación. En los otros casos, la información solicitada no requería mucho trabajo o esfuerzo para su elaboración, incluso en alguno de ellos, como en Társaság, ya estaba lista y disponible para ser entregada. ${ }^{63}$ En este caso, la carga de trabajo para la autoridad sería considerable. Sin embargo, que esta demanda de acceso supusiera una grave carga, a juicio del TEDH, era solo responsabilidad de la autoridad nacional, puesto que sus decisiones son consideradas de interés público y por ello deberían ser publicadas de una u otra forma. No obstante, no tenía publicada ninguna y esto es lo que ocasionó en gran parte su negativa a facilitar el acceso a la ONG demandante. ${ }^{64}$ En consecuencia, aunque el TEDH no se entrometió en determinar de qué manera debería o podría la autoridad nacional haber dado acceso a sus decisiones, sentenció de manera clara que la negativa absoluta de permitir acceso a sus decisiones fue desproporcionada ${ }^{65}$ y debido a que esa decisión dependió totalmente de

61 STEDH Österreichische Vereinung c. Austria, párrafos 33 y 34.

62 STEDH Österreichische Vereinung c. Austria, párrafo 34. Véase, por ejemplo, STEDH Satakunnan Markkinapörssi Oy and Satamedia Oy c. Finlancia, de 27 de junio de 2017, párrafo 128; STEDH Shapovalov c. Ukraine, de 31 de julio de 2012, párrafo 68; STEDH Dammann c. Suiza, 25 April 2006, párrafo 52; STEDH Sunday Times c. Reino Unido (n o 2), 26 de noviembre de 1991, párrafo 51.

63 STEDH Österreichische Vereinung c. Austria, párrafo 44.

64 STEDH Österreichische Vereinung c. Austria, párrafo 46.

65 En contra de esta valoración se pronuncia en un voto particular disidente el juez Møse. 
ella y que además ostentaba el monopolio informativo respecto de sus decisiones, hizo imposible que la ONG demandante pudiera llevar a cabo su actividad investigadora. ${ }^{66}$ Por todo ello, el TEDH concluyó que la injerencia en el art. $10 \mathrm{CEDH}$ de la demandante no fue necesaria en una sociedad democrática.

En Roşiianu c. Rumania, de 24 de febrero de 2014, la Sección Tercera del TEDH conoció de la demanda planteada por una periodista rumana que realizó varias solicitudes de información pública al alcalde de Baia Mare, donde presentaba un programa de televisión sobre la utilización de los fondos públicos por parte del municipio. La información solicitada versaba sobre cuestiones claramente de carácter público como los viajes del alcalde y de los funcionarios del ayuntamiento, los contratos de publicidad del consistorio, los gastos en organizar festivales públicos, los costes de mantenimiento de los vehículos oficiales, la retribución del alcalde por ser miembro de empresas dependientes del ayuntamiento... etc. Ante la presentación de una información incompleta y la condena por parte de las autoridades judiciales, el alcalde no ejecutó las decisiones judiciales.

El TEDH entendió vulnerado el art. $10 \mathrm{CEDH}$ debido a que la actitud del alcalde no facilitó la información pública solicitada por un miembro de la prensa, colectivo cuyo principal cometido es generar debate público. Por ello, a juicio del Tribunal de Estrasburgo, no se puede permitir que las restricciones arbitrarias puedan transformarse en una forma de censura indirecta al impedir la recopilación de información. ${ }^{67}$

En Guseva c. Bulgaria, de 17 de febrero de 2015, la Sra. Guseva, miembro de una ONG centrada en el cuidado de los animales, demandó al alcalde de su ciudad por no dar cumplimiento a tres decisiones judiciales que le daban la razón a demandas de suministro de información sobre campañas de cuidado de animales en esa ciudad y contribuir al debate público sobre la protección de los animales. La primera solicitud trataba de información sobre animales abandonados en la ciudad; la segunda requería información estadística de 2001 y 2002 de un refugio de animales municipal; y la tercera, información relativa al procedimiento de contratación pública que había sido organizada por el alcalde con el fin de reducir el número de perros callejeros.

En esta sentencia el TEDH partió de que la solicitud de la demandante entraba dentro del ámbito del art. $10 \mathrm{CEDH}$, destacando la labor de las ONGs para generar debate público, la necesidad de proteger su labor como a la prensa, y reconociendo que la tarea de reunir información para aportarlo al debate público es una parte inherente del derecho a la libertad de expresión. Por tanto, la negativa de facilitar información constituyó una injerencia al derecho a difundir información de la demandante. La cuestión particular de este caso es que la demandante de información no es la ONG defensora de los animales, sino la Sra. Guseva a título individual. ${ }^{68}$ Sin embargo, esto no supuso ningún problema para el TEDH, con lo que dio un paso más en el proceso de extender el art. $10 \mathrm{CEDH}$ desde los informantes profesionales, a las sociedades no gubernamentales y a las personales particulares. El TEDH finalmente decretó la vulneración del derecho fundamental ${ }^{69}$

66 STEDH Österreichische Vereinung c. Austria, párrafo 47.

67 STEDH Roşiianu c. Rumania, párrafos 61-68.

68 STEDH Guseva c. Bulgaria, 17 de febrero de 2015, párrafo 55.

69 Con dos votos disidentes en contra de los magistrados Mahoney y Wojtyczek que se inclinaban por la línea jurisprudencial mantenida en los casos Leander, Gaskin, Guerra y Roche. 
pues además de que el alcalde, que tenía toda la información requerida, se negó obstinadamente a cumplir las sentencias judiciales, la legislación nacional no determinaba el periodo de tiempo en el que se tenía que dar cumplimiento a las decisiones judiciales. $^{70}$

Esta serie de decisiones en las que puede apreciarse claramente el carácter instrumental del derecho de acceso a la información para hacer efectivo el derecho de información de los demandantes, fue sintetizada y aclarada por la Gran Sala en la importantísima STEDH Magyar Helsinki Bizottság c. Hungría, de 8 de noviembre de 2016. La ONG Magyar Helsinki Bizottság (Comité Húngaro Helsinki) cuyo cometido es vigilar la implementación de los estándares de derechos humanos fijados en instrumentos internacionales en Hungría, llevó a cabo una serie de proyectos para estudiar, entre otras cosas, el sistema para el nombramiento ex officio de abogados defensores en casos penales. Con la finalidad de sugerir un procedimiento automatizado que solucionara algunos de los problemas detectados en el nombramiento de abogados defensores que realizaba la misma policía húngara, como falta de transparencia, independencia y la consecuente falta de confianza por parte de los acusados en el procedimiento, la ONG solicitó a 28 departamentos de policía de 7 regiones el nombre de los abogados de oficio y sus asignaciones a casos, con el objetivo de «demostrar si existían discrepancias en la práctica de los departamentos de policía al designar abogados defensores de las listas proporcionadas por los colegios de abogados.» La ONG realizó esta petición, bajo la Ley de Datos húngara de 1992, considerando que el número de nombramientos de abogados defensores era de interés público y, por tanto, los nombres de los abogados defensores eran datos sujetos a divulgación en interés público. La mayoría de los departamentos de policía facilitaron los datos pero dos concretamente se negaron alegando que los nombres de los abogados defensores no formaban parte de un órgano estatal y por tanto sus datos eran privados, quejándose además de la «carga desproporcionada» de trabajo que supondría cumplir con esa solicitud. Tras una sentencia favorable en primera instancia, el tribunal de apelaciones y el Tribunal Supremo húngaro consideraron que los abogados defensores no ejercitaban ninguna labor pública, por lo que bajo la Ley de Datos húngara los nombres y el número de nombramientos de los abogados eran datos personales y no existía un deber de entregarse. La ONG acudió al TEDH considerando que la negativa al acceso a la información pública por parte de los departamentos de la policía suponía una vulneración del art. $10 \mathrm{CEDH}$.

La importancia de esta STEDH radica en que la Gran Sala se centró en resolver definitivamente la debatida y controvertida cuestión de fondo que subyacía en todos los casos explicados anteriormente, esto es, si el art. $10 \mathrm{CEDH}$ puede ser interpretado de un modo que garantice a la demandante ONG un derecho de acceso a la información en posesión de las autoridades públicas ${ }^{71}$.

El TEDH pretendió clarificar los principios ya existentes o considerados por él mismo como «clásicos» presentes en su jurisprudencia sobre el derecho o de acceso a la información pública. En este sentido, el TEDH continuó considerando, en primer lugar, que el derecho a la libertad de recibir información básicamente prohíbe que un gobierno

70 STEDH Guseva c. Bulgaria, 17 de febrero de 2015, párrafos 57-60.

71 STEDH Magyar Helsinki Bizottság c. Hungría, párrafo 71. 
restrinja o limite que una persona reciba información de otras que deseen o quieran dársela»; en segundo lugar, que el derecho a recibir información no puede interpretarse como una obligación positiva del Estado de recopilar y difundir información de oficio»; y en tercer lugar, que el art. $10 \mathrm{CEDH}$ no confiere a la persona un derecho de acceso a la información en poder de una autoridad pública ni obliga al Gobierno a transmitir dicha información a la persona.

Sin embargo, dicho derecho u obligación puede surgir en dos circunstancias: en primer lugar, cuando la divulgación de la información ha sido impuesta por una orden judicial que ha adquirido fuerza legal (que no es un problema en el presente caso) ${ }^{72}$; y, en segundo lugar, en circunstancias en que el acceso a la información sea instrumental para el ejercicio individual de su derecho a la libertad de expresión, en particular «la libertad de recibir y difundir información» y su negativa constituya una injerencia en ese derecho ${ }^{73}$.

En definitiva, el TEDH consideró que la información solicitada era sin duda de carácter público y relevante, y necesaria para completar el proyecto sobre el funcionamiento del plan de defensores públicos con el fin de contribuir a la discusión sobre un tema de interés público. Al denegarle el acceso a la información solicitada, que estaba lista y disponible, las autoridades nacionales menoscabaron el ejercicio por parte de la ONG solicitante de su libertad de recibir y difundir información, de una manera que afectaba a la esencia de sus derechos en virtud del artículo 10. Por lo tanto, el TEDH sentenció que la negativa de los departamentos de policía supuso una interferencia, no justificada ni necesaria en una sociedad democrática a los derechos reconocidos en el art. 10.1 CEDH. El TEDH insistió mucho en el carácter instrumental con el que la ONG demandaba su tutela, afirmando que «El Tribunal está convencido de que la ONG solicitante deseaba ejercer el derecho a difundir información sobre un asunto de interés público y buscó acceso a la información con ese fin.» Por ello, la información era necesaria para el ejercicio de su derecho a la libertad de expresión. De esta manera, el TEDH, a través de una decisión de Gran Sala, cristalizó los principales criterios que ya había utilizado en otras decisiones anteriores para determinar, caso a caso y bajo las circunstancias particulares, «si y en qué medida la denegación de acceso a la información constituye una interferencia con los derechos de libertad de expresión del solicitante», definiendo de esta manera el ámbito de este derecho. Estos criterios que el TEDH señaló, y a los que se hará referencia con más detenimiento más adelante son, en primer lugar, el propósito de la información solicitada, en segundo lugar, la naturaleza de la información buscada, en tercer lugar, el papel del demandante de la información, y en cuarto lugar la disponibilidad de la información solicitada ${ }^{74}$.

$72 \mathrm{El} \mathrm{TEDH}$ ha tenido siempre en cuenta la existencia del derecho al acceso a la información pública en la legislación y realidad judicial nacional para el reconocimiento de dicho derecho en el ámbito del art. 10 CEDH. Véase, por ejemplo, la decisión de Gran Sala Gillberg c. Suecia, de 3 de abril de 2012 en la que el Tribunal de Estrasburgo argumentó que un derecho a recibir información reconocido en el Estado de origen podría hacer surgir un derecho amparado en el art. $10 \mathrm{CEDH}$ (párrafo 93). Este es un caso peculiar, en el que el TEDH sustancia si la negativa de un médico pediatra a difundir información de expedientes e información de estudios e investigaciones médicas propiedad de la Universidad conculca sus derechos del art. $8 \mathrm{CEDH}$ y $10 \mathrm{CEDH}$. El TEDH acabó sentenciando que tales derechos no son de aplicación a ese caso.

73 STEDH Magyar Helsinki Bizottság c. Hungría, párrafo 156.

74 STEDH Magyar Helsinki Bizottság c. Hungría, párrafos 177, 172 y 175, 156 y 158-170, respectivamente. 


\section{Próximo reto: ¿el reconocimiento del derecho de acceso como componente instrumental del derecho a la tutela judicial efectiva (art. 6.1 CEDH)?}

Para poder abordar en esta cuestión, es imprescindible afirmar previamente que el TEDH no solo ha reconocido en varias ocasiones que el derecho a la libertad de expresión del art. 10.1 CEDH constituye un derecho civil a los efectos del art. 6.1 $\mathrm{CEDH}^{75}$, sino que lo ha afirmado del derecho de acceso en términos categóricos: «el Tribunal considera que el derecho de acceso a documentos particulares, que entran dentro de la libertad de expresión del demandante, es un «derecho civil» para los efectos del art. 6.1 de la Convención.» ${ }^{76}$

Dicho esto, en nuestra opinión, y con base en la jurisprudencia del TEDH, el derecho de acceso a la información puede constituir también una herramienta imprescindible para un derecho de la trascendencia de la tutela judicial efectiva, en sus diferentes contenidos. No obstante, el TEDH no ha solido tratar estos dos derechos de manera conjunta de manera clara ${ }^{77}$, aunque recientemente la Gran Sala ha dictado una decisión interesante sobre la revelación o no de pruebas clasificadas como secreto.

En la sentencia de Gran Sala Regner c. República Checa de 19 de septiembre de 2017 el demandante, un alto funcionario del Gobierno checo que llegó a ser Vice ministro de Defensa fue privado de su «autorización de seguridad» sin obtener una explicación satisfactoria. Tras impugnar la decisión, en los procedimientos administrativos y judiciales los servicios de seguridad checos aportaron un resumen de informes y pruebas que aconsejaban la revocación de su autorización, pero al contener información clasificada no pudo acceder a los mismos, ni por tanto, defenderse de lo que pudieran afirmar en su contra. Es decir, el demandante no pudo acceder a pruebas decisivas aportadas por la otra parte por estar clasificadas como confidenciales, ni en vía administrativa ni en vía judicial. Los tribunales nacionales solo consultaron los resúmenes de los informes, pero no los originales. El Sr. Regner consideró que sufrió indefensión, ya que las decisiones se basaban en esos informes, y denunció una vulneración a su derecho a la tutela judicial efectiva (art. 6.1 CEDH, concretamente el principio de igualdad de armas). La Gran Sala del TEDH no consideró la vulneración pretendida por el demandante (10 votos a favor y 7 en contra), basándose en que el principio de igualdad de armas no es absoluto, pudiendo matizarse en ocasiones, como por ejemplo en presencia de intereses nacionales superiores. El TEDH reiteró que el derecho a revelar las pruebas no es un derecho absoluto pero que solo medidas que no restringieran la verdadera esencia de los derechos de una de las partes sería permitido bajo el art. 6.1 CEDH, por lo que «cualquier dificultad que se le ocasione a la parte demandante por una limitación de sus derechos debe ser suficientemente contrarrestada por los procedimientos seguidos por las autoridades judiciales.» ${ }^{78}$ Consideró que la clasificación de los documentos no se había realizado por motivos arbitrarios

75 Véase, por ejemplo, Kenedi c. Hungría, párrafo 33.

76 Véase, por todas, la STEDH Shapovalov c. Ucrania, de 31 de julio de 2012, párrafo 49

77 Por ejemplo, en Kenedi c. Hungría, la violación del art. 6.1 CEDH fue reconocida porque las autoridades húngaras tardaron muchísimo tiempo en ejecutar las sentencias que le reconocía el derecho a acceder a unos documentos; en STEDH Sdružení Jibočeské Matky c. República Checa dejó la cuestión de la tutela judicial efectiva abierta para los tribunales nacionales.

78 STEDH Regner c. República Checa, párrafos 146-149. 
y que los tribunales nacionales habían dado razones fundamentadas para apoyar la revocación de la autorización de seguridad del demandante. Los votos discordantes con la decisión mayoritaria implicaba el reconocimiento de la importancia del acceso a información en posesión de autoridades estatales, aunque no enfocaron su argumentación desde ese punto de vista de manera explícita. El voto particular de los magistrados Raimondi, Sicilianos, Spano, Ravarani y Vilanova consideraron la violación del art. 6.1 CEDH porque el no acceso a los informes impidió tener una defensa adecuada al demandante, al estimar que lo contenido en los informes de la inteligencia hubiera sido comprobado lo suficiente como para que fuera una verdad indubitada. Tampoco creyeron adecuado el rol que adoptaron los tribunales nacionales, como defensores del demandante, sustituyendo a su defensa. El magistrado Sajó fue más vehemente en su crítica al voto mayoritario, puntualizando que también el art. $8 \mathrm{CEDH}$ estaba afectado en este caso, afirmando que «Cuando las personas acusadas de delitos civiles o penales puedan ser ignoradas por completo sobre la base de los cargos en su contra, y cuando las autoridades de seguridad nacional puedan tomar decisiones sin razones y justificación adecuadas ante los tribunales nacionales, los ciudadanos no estarán protegidos contra el abuso estatal arbitrario».

El derecho de acceso, por tanto, no fue discutido como tal, pero sin duda era la cuestión esencial para decidir sobre la correcta o desacertada actuación judicial y, por tanto, vulneración del art. 6.1 CEDH.

\section{CONTORNOS DEL DERECHO DE ACCESO A LA INFORMACIÓN DESDE LA TEORÍA GENERAL DE DERECHOS FUNDAMENTALES}

De la jurisprudencia dictada por el TEDH se pueden ir perfilando ciertos contornos, limitaciones o significados de un derecho instrumental de acceso a la información pública, que conforme a la teoría general de los derechos fundamentales se agruparían en titularidad, objeto y límites del citado derecho.

\section{Titularidad del derecho}

Partiendo del carácter instrumental que el TEDH ha caracterizado al derecho de acceso a la información, la titularidad de semejante derecho ha de ser definida a través del mismo carácter instrumental, es decir, corresponderá a toda aquella persona que, bajo una serie de circunstancias necesarias, necesite esa información para hacer efectivo su derecho a la libertad de expresión, a la vida privada personal y familiar y, desde nuestro punto de vista, incluso a la tutela judicial efectiva (aunque sobre este derecho el TEDH no se ha pronunciado en esos términos), además de aquellas personas a las que un juez nacional le haya reconocido el derecho de acceso.

Por tanto, respecto del acceso para hacer efectivo el derecho a la libertad de expresión, ha de aclararse si la información buscada es de hecho necesaria para el ejercicio de la libertad de expresión, "para recibir y difundir información e ideas a otras personas».

El ejemplo paradigmático serían los periodistas o la prensa en general, pues la actividad de investigación y de recabar información es el paso esencialmente prioritario en el 
periodismo ${ }^{79}$ y parte protegida e inherente de la libertad de prensa ${ }^{80}$. Generar debate público sigue siendo una parte esencial del trabajo de la prensa y por ello se le debe permitir buscar información con relevancia ${ }^{81}$, incluso aunque sean cuestiones clasificadas y susceptibles de no ser filtradas por seguridad nacional ${ }^{82}$. En el trabajo de buscar se incluye estar en los sitios donde se esté desarrollando un acontecimiento de interés público como poder presenciar in situ un debate legislativo sin ser expulsados ${ }^{83}$.

Por otro lado, de manera insistente el TEDH ha reconocido que la función de crear plataformas para el debate público no está limitado a la prensa, mucho menos en la actualidad con la revolución que ha supuesto Internet ${ }^{84}$. Esa función puede ser ejercitada también por las organizaciones no gubernamentales que destinan sus esfuerzos a fomentar un debate público, buscando información, recopilándola y difundiéndola a la sociedad. De esta manera se constituyen cada vez más como un elemento esencial de un debate público informado. Por ello, el TEDH ha aceptado que las organizaciones no gubernamentales, al igual que la prensa, puedan ser caracterizadas como «social watchdogs» $\mathrm{y}$, en coherencia, sus actividades merezcan una protección similar bajo el CEDH a las de la prensa. Este paralelismo de aumentar la protección de las ONGs lo estableció el TEDH en primer lugar en Társaság a Szabadságjogokért ${ }^{85}$, y la ha mantenido de manera inamovible en decisiones posteriores ${ }^{86}$. En consecuencia, las ONGs cuya labor se centra en fomentar el debate público a través de buscar información y difundirla a la sociedad son titulares del derecho de acceso a la información pública en poder de la autoridades públicas.

Además, el TEDH ha ampliado el supuesto anterior reconociendo la legitimidad activa en la demanda de una activista que no litigaba en nombre de la ONG con fines de interés público a la que pertenecía, sino como persona a título individual ${ }^{87}$. Sin embargo, esto no supuso ningún problema para el TEDH, con lo que dio un paso más en ampliar la legitimidad activa del art. $10 \mathrm{CEDH}$ desde los informantes profesionales a las sociedades no gubernamentales y a las personales particulares. Por tanto, el TEDH extiende esta titularidad a sujetos particulares o individuales ${ }^{88}$ siempre y cuando sus actividades estén

79 «La función vital de los medios de comunicación para facilitar y fomentar el derecho del público a recibir y difundir información e ideas ha sido reiteradamente reconocida por el Tribunal. La prensa no solo tiene la tarea de impartir dicha información e ideas; el público también tiene derecho a recibirlos. Si no fuera así, la prensa no podría desempeñar su papel vital como «vigilante público» STEDH Satakunnan Markkinapörssi Oy and Satamedia Oy c. Finalndia, de 27 de junio de 2017, párrafo 126.

80 «Está bien establecido que la recopilación de información es un paso preparatorio esencial en el periodismo y una parte inherente y protegida de la libertad de prensa» STEDH Satakunnan Markkinapörssi Oy and Satamedia Oy c. Finalndia, de 27 de junio de 2017, párrafo 128; STEDH Shapovalov c. Ucracia, 31 de julio de 2012, párrafo 68; STEDH Dammann c. Suiza, 25 de abril de 2006, párrafo 52.

81 STEDH Roşiianu c. Rumania, de 24 de febrero de 2014, párrafos 62 y 63; STEDH Shapovalov c. Ucrania, de 31 de julio de 2012;

82 STEDH Gîrleanu c. Rumanía, de 26 de Junio de 2018.

83 STEDH Selmani y otros c. La Ex República Yugoslava de Macedonia, de 9 de febrero de 2017.

84 Véase el voto particular de los magistrados Sajó y Vučinić en STEDH Társaság a Szabadságjogokért c. Hungría.

85 STEDH Társaság a Szabadságjogokért c. Hungría, párrafo 27.

86 STEDH Österreichische vereinigung... c. Austria, párrafo 34; STEDH Animal Defenders International c. Reino Unido, párrafo 103; STEDH Youth Initiative for Human Rights c. Serbia, párrafo 20; STEDH Guseva c. Bulgaria, párrafo 54.

87 STEDH Guseva c. Bulgaria, 17 de febrero de 2015.

88 En la misma línea que sostiene el Comité de Derechos Humanos de Naciones Unidas, véase, por ejemplo, Toktakunov c. Kyrgyzstan (Comunicación No. 1470/2006, 28 marzo 2011) 
relacionadas con la recopilación legítima de información de interés público con el propósito de contribuir al debate público ${ }^{89}$. La Corte también señalaría que dado el importante papel desempeñado por Internet para mejorar el acceso público a las noticias y facilitar la difusión de información ${ }^{90}$ «la función de los blogueros y los usuarios populares de las redes sociales también puede asimilarse a la de los «vigilantes públicos» en la medida en que se refiere a la protección del Artículo 10.» ${ }^{91}$

Por último, y relacionado con la titularidad anterior, el TEDH ha reconocido el papel importante de aquellas personas que contribuyen al conocimiento y debate público, desarrollando actividades de investigación al solicitar acceso a fuentes originales históricas y publicando el fruto de esas investigaciones. En este contexto, el TEDH ha entendido que este acceso constituye un elemento esencial del derecho a la libertad de expresión del demandante, ${ }^{92}$ reitera que un alto nivel de protección también se extiende a los investigadores académicos ${ }^{93}$ e incluso autores de literatura sobre asuntos de interés público ${ }^{94}$.

Para terminar, aunque no podemos extendernos sobre este tema, al explicar la titularidad desde la teoría de los derechos también habría que hacer mención a los obligados por esos derechos. En el caso del derecho de acceso dentro de la libertad de expresión, el TEDH ha afirmado que existen obligaciones positivas para el Estado, prohibiendo a los Estados parte establecer impedimentos o crear problemas por parte de las autoridades públicas para acceder a la información de interés público, pues podría desanimar a aquellos que pretendan contribuir al debate público, dejando de jugar su esencial rol de «public watchdogs»; del mismo modo, su habilidad para conseguir información exacta y fiable podría verse afectada. Por todo ello, el TEDH es constante en sentenciar que se pone en riesgo el derecho a difundir información de la parte demandante, máxime si ya ha habido decisiones de las autoridades nacionales reconociendo ese derecho de acceso ${ }^{95}$.

El TEDH, además, impone a las autoridades públicas adoptar un escrutinio más cuidadoso con las decisiones negativas a conceder acceso a la información cuando de esas medidas pueda deducir un efecto disuasorio en la participación en el debate público sobre asuntos de temática pública ${ }^{96}$. Este escrutinio se debe extremar también cuando la información solicitada la ostente solamente un órgano público concreto, es decir, cuando ese órgano ostente el monopolio sobre esa información. ${ }^{97}$

El TEDH ha prestado mucha atención a las circunstancias concretas del caso al determinar la violación de un derecho de la CEDH por negar el acceso a una información.

89 STEDH Guseva c. Bulgaria, 17 de febrero de 2015, párrafo 55.

90 Véase SETDH Delfi AS v. Estonia, párrafo 133.

91 STEDH Magyar Helsinki Bizottság c. Hungría, párrafo 168.

92 Véase, por ejemplo, STEDH Kenedi c. Hungría, 26 de mayo de 2009, párrafo 43.

93 Véanse, por ejemplo, STEDH Başkaya y Oķ̧uoğlu c. Turquía, de 8 de julio de 1999, párrafos 61-67; STEDH Kenedi c. Hungría, párrafo 42 y STEDH Gillberg c. Suecia, párrafo 93.

94 STEDH Chauvy y otros c. Francia, párrafo 68; SEDH Lindon, Otchakovsky-Laurens y Julio c. Francia, 22 de octubre de 2007.

95 STEDH Guseva c. Bulgaria, 17 de febrero de 2015; STEDH Kenedi c. Hungría, 26 de mayo de 2009; STEDH Youth Initiative for Human Rights c. Serbia, 25 de junio de 2013.

96 STEDH Társaság a Szabadságjogokért c. Hungría, 14 de abril de 2009, párrafo 26; STEDH Thorgeir Thorgeirson c. Islandia, 25 de junio de 1992, párrafo 63; STEDH Jersild v. Denmark, 23 de septiembre de 1994, párrafo 35; STEDH Bladet Tromsø and Stensaas c. Noruega, 20 de mayo de 1999, párrafo 64.

97 STEDH Társaság a Szabadságjogokért c. Hungría, 14 de abril de 2009; STEDH Guseva c. Bulgaria, 17 de febrero de 2015 . 
Por ejemplo, no es lo mismo la solicitud de planos sobre una central nuclear ${ }^{98}$, que medidas de seguridad para la población circundante de una planta química ${ }^{99}$ que expedientes secretos sobre información personal ${ }^{100}$, o archivos en los que una persona sale pero no es el objeto en concreto o principal de los mismos ${ }^{101}$. Además, el derecho de acceso debería apuntalarse más si cabe en aquellos países que han sufrido dictaduras soviéticas y tienen una inercia muy difícil de vencer por parte de las autoridades públicas para conceder acceso de información pública, principalmente respecto de aquella información que se utilizaba para reprimir a los ciudadanos. ${ }^{102}$

Respecto de la vida privada personal o familiar el titular vendría definido por el interés personal que pudiera ostentar, esto es, las que ostenten un interés personal sobre la misma, demandando información que pueda afectar de manera perjudicial a aspectos vitales en caso de negativa.

En el caso de Guerra y otros c. Italia, la demanda de información era relevante para evaluar y evitar un riesgo para su salud e incluso para su vida. En los casos de Roche c. Reino Unido y Ginley y Egan c. Reino Unido, lo reclamado era información relativa a su salud para tomar posteriores medidas legales. De la misma manera, pero sobre cuestiones no tan relacionadas con la integridad física, en Leander c. Suecia y en Gaskin c. Reino Unido eran particulares que solicitaban información sobre un expediente secreto elaborado sobre su persona y expedientes con información sobre su vida pasada.

\section{Objeto del derecho}

De manera general podría afirmarse que el objeto del derecho de acceso lo constituiría la información solicitada que debe ostentar un carácter público, noticiable o relevante para generar opinión pública o debate en la sociedad, o conseguir alguna de las finalidades de los derechos reconocidos en el art. 10.1 CEDH; o relevante para la vida privada personal o familiar de quien la solicita conforme al art. $8 \mathrm{CEDH}$.

En este sentido, podrían apuntarse tres características, las dos primeras imprescindibles.

La primera característica hace referencia a que, partiendo de los casos ya resueltos ${ }^{103}$, el TEDH considera que la información, datos o documentos cuyo acceso se solicita, debe reunir un test de interés público, con el fin de generar una necesidad de divulgación en virtud

98 STEDH Sdružení Jihočeské Matky c. República Checa, de 19 de julio de 2006 (decisión).

99 STEDH Guerra y otros c. Italia, 19 de febrero de 1998.

100 STEDH Leander c. Suecia, 26 de marzo de 1987.

101 STEDH Gaskin c. Reino Unido, 7 de julio de 1989.

102 Voto particular del magistrado Sajó en STEDH Youth Initiative for Human Rights c. Serbia, 25 de junio de 2013.

103 El Tribunal determinó previamente que la denegación de acceso a la información constituía una interferencia con el derecho de los solicitantes de recibir e impartir información en situaciones donde los datos buscados eran «información objetiva sobre el uso de medidas de vigilancia electrónica» (véase STEDH Youth Initiative for Human Rights c. Serbia, párrafo 24), «información sobre una queja constitucional» y «sobre un asunto de importancia pública» (véase STEDH Társaság a Szabadságjogokért c. Hungría, párrafos 37-38), «fuentes documentales originales para la investigación histórica legítima» (véase STEDH Kenedi c. Hungría, párrafo 43), y las decisiones relativas a las comisiones de transacción de bienes inmuebles (véase STEDH Österreichische Vereinigung... c. Austria, párrafo 42), otorgando gran importancia a la presencia de categorías particulares de información que se consideran de interés público. 
del CEDH. Concretamente el TEDH considera que «Tal necesidad puede existir cuando, entre otras cosas, la divulgación proporciona transparencia sobre la manera de conducir los asuntos públicos y sobre asuntos de interés para la sociedad como un todo y de ese modo permite la participación en la gobernanza pública por parte del público en general» ${ }^{104}$. Más concretamente, el TEDH ha subrayado que la definición de lo que podría consistir una materia de interés público dependerá de las circunstancias de cada caso. «El interés público se relaciona con asuntos que afectan al público de tal manera que puede legítimamente interesarse por ellos, que atraen su atención o que le preocupan en gran medida, especialmente porque afectan el bienestar de los ciudadanos o la ciudadanía o vida de la comunidad. Este es también el caso con respecto a asuntos que pueden suscitar una controversia considerable, que se refieren a un problema social importante, o que involucran un problema que al público le interesa tener informado», pero por supuesto el interés público no puede reducirse a la sed pública de información sobre la vida privada de otros, o al deseo de una audiencia de sensacionalismo o incluso voyeurismo ${ }^{105}$.

La segunda característica hace referencia a que la información debe estar en posesión de un organismo público, constituyendo una especificidad respecto del objeto del derecho a la libertad de expresión que podría estar también en posesión de sujetos particulares.

De la jurisprudencia analizada, los órganos pertenecientes al poder ejecutivo son los que reciben más solicitudes de información. El gobierno central es el órgano estatal que más veces ha recibido demandas por no entregar la información solicitada ${ }^{106}$, ya fuera diferentes Ministerios como el de Interior ${ }^{107}$, Defensa ${ }^{108}$, Salud y Medioambiente ${ }^{109}$, Servicios de Inteligencia ${ }^{110}$ o Departamentos de Seguridad Social ${ }^{111}$. Sin embargo, también otros niveles administrativos han recibido demandas, como los pertenecientes a la administración regional ${ }^{112}$ y a la local ${ }^{113}$. También los órganos judiciales son susceptibles de recibir solicitudes de acceso a la información en su poder, como sucedió en Társaság a Szabadságjogokért c. Hungría con el Tribunal Constitucional húngaro. ${ }^{114}$

Por último, la tercera característica, no obligatoria en este caso, haría referencia a que la autoridad pública a la que se solicite la información la ostente en régimen de monopolio, es decir, es el único organismo que tiene esa información, no se puede conseguir por ningún otro cauce o acudiendo a otras autoridades. En este caso, el TEDH impone que el escrutinio a la negativa a conceder esa información se debe extremar ${ }^{115}$.

104 STEDH Magyar Helsinki Bizottság c. Hungría, párrafo 161

105 STEDH Magyar Helsinki Bizottság c. Hungría, párrafo 162

106 STEDH Leander c. Suecia, 26 de marzo de 1987.

107 STEDH Kenedi c. Hungary, 26 de mayo de 2009.

108 STEDH Roche c. Reino Unido, 19 de octubre de 2005

109 STEDH Guerra y otros c. Italia, 19 de febrero de 1998; STEDH SdruženíJibočeské Matky c. República Checa, de 19 de julio de 2006 (decisión).

110 STEDH Youth Initiative for Human Rights c. Serbia, 25 de junio de 2013.

111 STEDH McGinley y Egan c. Reino Unido, 28 de enero de 2000.

112 STEDH Österreichische vereinigung ... c. Austria, de 28 de noviembre de 2013

113 STEDH Guseva c. Bulgaria, 17 de febrero de 2015; STEDH Roşiianu c. Rumania, de 24 de febrero de 2014; STEDH Gaskin c. Reino Unido, 7 de julio de 1989

114 Aunque no son órganos judiciales, tomaban decisiones en procesos contenciosos las comisiones regionales en STEDH Österreichische vereinigung ...c. Austria, de 28 de noviembre de 2013.

115 STEDH Társaság a Szabadságjogokért c. Hungría, 14 de abril de 2009; STEDH Guseva c. Bulgaria, 17 de febrero de 2015. 


\section{Límites del derecho}

Teniendo en cuenta que no es necesario justificar un interés personal para solicitar una información pública ${ }^{116}$, por lo que no puede constituir una limitación, hay dos límites específicos ${ }^{117}$ importantes a este derecho de acceso a la información pública visibles en la jurisprudencia del TEDH.

El primero ya se ha señalado insistentemente a lo largo de estas páginas. No existe una obligación positiva de los Estados de facilitar información en su poder. El Tribunal de Estrasburgo se ha pronunciado de manera taxativa y constante respecto del art. 10 CEDH. ${ }^{118}$ Es interesante señalar la peculiaridad que supone en esta línea el caso Österreichische vereinigung ...c. Austria. Como ya se ha expuesto, la autoridad regional no había publicado nunca ninguna decisión sobre los pleitos contenciosos que resolvía, y solo ella tenía esa información. Esta falta de publicación fue la razón aducida por el organismo para no facilitar la información solicitada. El TEDH reprochó que la falta absoluta de publicidad de las decisiones de la autoridad nacional fuera una de las razonas por las que no concediera acceso a la información solicitada, y al estimarlo de su única responsabilidad, sentenció la vulneración del art. $10 \mathrm{CEDH}$. No impuso una obligación positiva de publicar, y el TEDH se abstuvo explícitamente de decir cómo y cuánto debería haberse publicado para no haber considerado no vulnerado el derecho de acceso a la información pública. Pero quedó implícito en la sentencia que la autoridad tirolesa debería publicar de manera periódica algún tipo de información sobre sus decisiones. Respecto del art. 8 $\mathrm{CEDH}$, como ya se ha apuntado en páginas anteriores, en la primera etapa jurisprudencial el Tribunal de Estrasburgo señaló la obligación positiva del Estado en ciertos casos, como por ejemplo, de prever procedimientos de acceso a la información solicitada ${ }^{119}$ efectivos y accesibles ${ }^{120}$, o de tomar las medidas suficientes para informar a la ciudadanía ${ }^{121}$.

En segundo lugar, el TEDH afirma que la solicitud de acceso ha de realizarse sobre un documento o serie de documentos determinados y concretos, no toda la documentación indiscriminada en un período de tiempo ${ }^{122}$. Si la documentación que se solicita está

116 En la línea también del Comité de Derechos Humanos de Naciones Unidas, véase Toktakunov c. Kyrgyzstan (Comuniación No. 1470/2006, 28 marzo 2011)

117 Además de los generales señalados en los arts. 10.2 CEDH y 8.2 CEDH y los que puedan constituir otros derechos fundamentales como la protección de datos (art. 8.1 CEDH).

118 Se ha alegado muy a menudo que el art. $10 \mathrm{CEDH}$ está redactado en términos negativos, garantizando el derecho a «recibir y difundir informaciones e ideas sin interferencias por las autoridades públicas». Este tenor negativo impediría la interpretación de la posible imposición de obligaciones positivas para los Estados para garantizar el acceso a su propia información. Sin embargo, esta expresión en negativo no ha impedido al TEDH establecer obligaciones positivas en otros contextos del derecho a la libertad de expresión. Por ejemplo, en Ozgur Gundem v. Turkey, 16 de marzo de 2000, párrafos 44-45, el TEDH mantuvo que el fallo de las autoridades turcas en tomar medidas para proteger un periódico de ataques de personas privadas, que silenciaron efectivamente la publicación, supusieron una violación del art. $10 \mathrm{CEDH}$. En consecuencia, se podría argumentar que la obligación del Estado de difundir información en su poder que sea de dominio público sea al menos tan obligatorio como el requisito de que el Estado cese o castigue las interferencias privadas con el libre flujo de información. El rechazo del Estado a proporcionar acceso podría suponer una interferencia con el libre flujo de información pública, una esfera que claramente incluye datos en posesión del Estado a nombre y en beneficio de la ciudadanía.

119 STEDH Gaskin c. Reino Unido, 7 de julio de 1989.

120 STEDH Roche c. Reino Unido, 19 de octubre de 2005.

121 STEDH Guerra y otros c. Italia, 19 de febrero de 1998.

122 STEDH Österreichische vereinigung ... c. Austria, de 28 de noviembre de 2013. 
elaborada, esto es, no requiere ningún esfuerzo o trabajo adicional del órgano requerido, es un elemento más para que el TEDH aprecie que debería concederse el acceso a la información ${ }^{123}$, o por el contrario rechazarse ${ }^{124}$. Es decir, el TEDH opina que el hecho de que la información objeto de la solicitud está lista y disponible debería constituir un criterio importante en la evaluación general de si la negativa a proporcionar la información puede considerarse como una «interferencia» con la libertad de «recibir y difundir información» como está protegido por esa disposición.» ${ }^{125}$

\section{A MODO DE CONCLUSIÓN}

Tras el estudio de la jurisprudencia del TEDH en materia del derecho de acceso a la información pública, el balance arroja luces, sobras y penumbras. Las luces corresponden a la elaboración jurisprudencial del derecho en el ámbito del art. 10.1 CEDH, culminado por la STEDH de Magyar Helsinki Bizottság c. Hungría. Las penumbras corresponden al desarrollo en materia de derecho a la vida privada y familiar, pues ha sido eclipsado casi completamente por el derecho a la libertad de expresión. Las sombras corresponden, por un lado, al conformismo o falta de audacia del TEDH de limitar el derecho de acceso a la información pública como meramente instrumental; por otro lado, a la falta de desarrollo de este derecho en el ámbito del art. 6.1 CEDH en materia principalmente de acceso a pruebas confidenciales en países con regímenes recientemente totalitarios. El carácter instrumental de este derecho no es malo por sí mismo, al contrario, su reconocimiento explícito es muy positivo. Sin embargo, con este reconocimiento da la sensación de que el TEDH ha llegado al límite en el reconocimiento de un derecho tan poliédrico como esencial en las democracias actuales, un reconocimiento que le queda aún mucho desarrollo, tanto como se demandan fórmulas participativas por parte de la ciudadanía. Sin información no se forjan actitudes críticas; sin actitudes críticas no se demanda más información para embridar al poder público. Con poderes públicos sin ser sometidos a una efectiva rendición de cuentas, tanto institucional como ciudadana, es cuestión de tiempo que la calidad democrática languidezca y la desafección ciudadana crezca. En un sistema tan complejo y delicado, en el que los Estados suelen adoptar posturas cicateras, el TEDH ha de ejercer un papel protagonista y llevar la iniciativa como tantas veces ha hecho en el desarrollo y garantía de otros derechos fundamentales.

TITLE: The right of Access to public information in the ECtHR case law: an instrumental right essential for the effectiveness of the European Convention from the general theory of rights

ABSTRACT: The debate on the recognition of the right of access to public information in the ECHR has dealt mainly with art. 10 ECHR. This has been reinforced by the last ECtHR ruling Magyar Helsinki Bizottsag v. Hungary (2016) that has been declared in the case law of the ECtHR since 2006, but highlighting its instrumental nature. However, this

123 STEDH Társaság a Szabadságjogokért c. Hungría, 14 de abril de 2009; STEDH Guseva c. Bulgaria, 17 de febrero de 2015; STEDH Roşiianu c. Rumania, de 24 de febrero de 2014.

124 Véase, STEDH Bubon c. Rusia, 7 de febrero de 2017, párrafo 40.

125 STEDH Magyar Helsinki Bizottság c. Hungría, párrafos 169 y 170. 
approach covers only one part, the main one, of the scope that protects the right of access to public information. Without paying attention to other rights pointed out in the ECHR jurisprudence through which access to public information has become effective, such as art. $8 \mathrm{ECHR}$ and art. $6.1 \mathrm{ECHR}$, also instrumentally, the definition of this important right would be unfinished. Therefore, through the general theory of fundamental rights, the constitutive elements of a fundamental right without explicit recognition in the text of the ECHR but very present in the jurisprudence of the ECHR are reconstructed.

RESUMEN: El debate en torno al reconocimiento del derecho de acceso a la información pública en el CEDH ha girado principalmente en torno al art. $10 \mathrm{CEDH}$. Esta postura se ha visto reforzada con la última sentencia de la Gran Sala Magyar Helsinki Bizottsag c. Hungria (2016) que ha dado carta de naturaleza al mencionado derecho descrito a pinceladas en la jurisprudencia del TEDH más o menos constante desde el 2006, pero destacando el carácter instrumental del mismo. No obstante, este enfoque abarca solo una parte, la principal sin duda, del ámbito que protege el derecho de acceso a la información pública. Sin prestar atención a otros derechos apuntados en la jurisprudencia del TEDH a través de los cuales se ha hecho efectivo el acceso a la información pública, como el art. $8 \mathrm{CEDH}$ y el art. $6.1 \mathrm{CEDH}$, también de manera instrumental, la definición de este importante derecho estaría inacabada. Por ello, a través de la teoría general de derechos fundamentales, se reconstruyen los elementos configuradores de un derecho fundamental sin reconocimiento explícito en el texto del CEDH pero muy presente en la jurisprudencia del TEDH.

KEY WORDS: Right of access to information; freedom of expression; right to private and family life; European Convention of Human Rights; European Court of Human Rights.

PALABRAS CLAVE: derecho de acceso a la información; libertad de expresión; derecho a la vida privada y familiar; Convenio Europeo de Derechos Humanos; Tribunal Europeo de Derechos Humanos.

FECHA DE RECEPCIÓN: 15.06.2018

FECHA DE ACEPTACIÓN: 13.09.2018

UNED. Teoría y Realidad Constitucional, núm. 42, 2018, pp. 483-509 
